\title{
Order Out of Chaos: Nudging Tourists’ Behaviours at a Time of Disruption?
}

\author{
Clive Smallman, Peter Ryan \\ Higher Education Leadership Institute, Sydney, Australia
}

\begin{abstract}
A set of major disruptive political, socio-economic, technological, and ecological trends presents serious issues for tourism policy makers, regulators, and operators alike. In this turbulent context, how best to attempt to predict tourist behaviours? In tourism research the dominant rationalistic approach to decision-making does provide some useful insights across tourism choice. However, it seems increasingly less suited to the often relatively unplanned, hedonic, opportunistic, and impulsive decision-making that often characterises tourists' behaviours on-site within a destination, and more generally to the behaviours of Generation Y and Generation Z. More generally, it is arguable that rational models of motivation and decision-making systematically underestimate the importance of affective processes in tourists' behaviours. In this paper, we explore the implications of employing a much more naturalistic approach to decision-making at both the policy level and at the frontline of tourism operations.
\end{abstract}

Keywords: tourist behaviours, decision-making, nudge theory, naturalistic decision-making

\section{Introduction: Disruptive Trends and Tourism}

That the world is changing is simultaneously cliché and a gross understatement. Radically different political, economic, social, technological, and environmental worlds are evolving at unprecedented rates (Dobbs, Manyika, \& Woetzel, 2015). As a result tourism is being disrupted (Dwyer, Edwards, Mistilis, Romand, \& Scott, 2009).

Political instability is on the rise, as terrorism incidents are worldwide. The literature suggests that the negative impact of political instability on tourism is more severe than is the case with single terrorist incidents. Paradoxically it has been found that countries with low to moderate political risk see an increase in tourism demand following attacks. However, tourism is certainly impacted in countries with high levels of political risk. This noted, terrorism and political instability together certainly impact tourism demand (Saha \& Yap, 2014).

Emerging markets such as China and India, and cities in those markets, have become new centres of rapidly expanding dynamic economic activity. That activity will intensify, further driving outbound tourism from those markets (Arlt, 2015; Fuller, 2017), although our approach to marketing will need to be adapted to further assure demand (Tsiotsou \& Ratten, 2010).

Socially, there are several major trends that are disrupting tourism. Medical technologies, along with increasing improvements in nutrition in much, but sadly not all of the world, mean that we are living longer. If we live longer we stay in work longer (Gratton \& Scott, 2016). Not only will this expand conventional tourism

Clive Smallman, Ph.D., Professor and Dean, Higher Education Leadership Institute, Sydney, Australia.

Peter Ryan, D.Prof., CEO, Higher Education Leadership Institute, Sydney, Australia. 
demand, but so-called "third age" or "silver hair" tourism will increase, with new types and forms of tourism and new service technologies evolving to match (Nikitin \& Vorontsova, 2015; Tsiotsou \& Ratten, 2010).

Generation Y (millennials) enjoy strong digital skills, are highly and permanently “connected”, and search for outstanding experiences, with a commitment to altruistic behaviours. This profile has seen an increase in the practice of volunteer tourism, search for places not connected with tourism as well as, (obviously) adoption of new, disruptive technologies. Whilst volunteer tourism is altruistic, it can harm destinations. Moreover, tourist incursions in destinations normally occupied only by residents can lead to the removal of locals from these places, and scopophobia (fear of visitors in your own home). Paradoxically then, it can degrade the very experiences that tourists seek. A further paradox in the behaviour of Generation $\mathrm{Y}$ is that the adoption of disruptive technologies by tourism agents to meet millennials' demands for immediate responses reduces the human interactions highly valued by millennials (Veiga, Santos, Águas, \& Santos, 2017).

Generation Z (post-millennials) are less focused, better multi-taskers, less price-sensitive, enter work earlier, are more entrepreneurial, have higher expectations, are defined by their individuality, and are more global than Generation Z (Beall, 2017). There is little research on the implications for tourism of this cohort, but it has been suggested that: They are conservative spenders with big ambitions who are inspired by the world, catching their intention is the ultimate challenge (video is best), they want a good (visual) story, and they want to contribute to their destinations' development (Fuggle, 2017). In other words, they are a more "intense" form of Generation Y.

We are also seeing the rise of a growing middle-class tourists' cohort with more disposable income, notably from China (Zeng \& Go, 2013) and India.

Demand from the cohorts cited above, coupled to economic development world-wide and investment in tourism marketing, is seeing unconventional destinations emerging, amongst them: Belgrade, Serbia; Dakar, Senegal; Baku, Azerbaijan; Caucasus Mountains, Georgia, and Panama City (CNT Editors, 2017).

Much of the dynamism of the changes previously outlined is driven by the rapidly accelerating evolution of information and communication technologies. And this is evolution not just of the technologies themselves, but in their impact, scale, and scope. Technology is transforming both tourism marketing (Gulbahar \& Yildirim, 2015) (notably in the loyalty space) as well as the tourism experience (Colomo-Palacios, García-Peñalvo, Stantchev, \& Misra, 2017).

Health and healthy lifestyle are increasingly important in tourists' decision making. "Silver hair” tourists, millennials and post-millennials, a growing middle class, and the technological and digital revolution, are boosting the importance of the health trend. Health and healthy lifestyle will become progressively more integrated into tourism offerings (Glover \& Stewart, 2013; Urh, 2015).

Environmentally, whilst contested by a vocal minority, sustainability is a pressing issue, and no more so than in tourism, given its hefty reliance on air travel and road transport (Becken \& Simmons, 2008), as well as local impacts in destination (Espiner \& Becken, 2013).

The search for improved understanding of complex interactions between tourists, tour operators, governments, and local communities has led to the development of models and general accounts of tourists' behaviours (Leiper, 2004). Whilst challenging to develop, these models have successfully influenced the management of tourists and their socio-economic and ecological impacts (Decrop, 2006).

However, aligning with previous work (Doscher, Moore, Smallman, Wilson, \& Simmons, 2014; McCabe, Li, \& Chen, 2016; Moore, Smallman, Wilson, \& Simmons, 2012; Smallman \& Moore, 2010; Smallman, Moore, Wilson, \& Simmons, 2012), we argue for a greater emphasis on "process” models of tourists' decision-making, 
and the consequential changes in ontology and epistemology they imply. We believe that this will help produce models of tourist decision-making that better suit the increasing concerns of how to manage the tourist experience in process in ways that minimise its adverse impacts, whilst retaining its central features of apparent spontaneity and freedom that many tourists value.

\section{Process Models of Tourists' Decision-Making}

Destination marketing and consumer services studies remain dominant in tourists' decision-making research. However, research into complex socio-economic and ecological dimensions of tourist behaviour is increasingly common (Lin \& Simmons, 2017; Shone, Simmons, \& Dalziel, 2016). Further, there is an increasing acceptance that tourists' decision-making is fluid and complex (Jun \& Vogt, 2013), reflecting broader trends in decision-making research (Gigerenzer, 2007; Gigerenzer \& Selten, 2002; Gigerenzer, Todd, \& the ABC Research Group, 1999; Kahneman, 2011; Thaler \& Sunstein, 2008).

There have been further calls to account for variance in choice strategies, how preferences are constructed, and the role of contextual, individual, and task-related factors in influencing choice. This requires models that contextually integrate the psychological processes that determine heuristic choice strategies (McCabe et al., 2016) and decision-rules (Li, McCabe, \& Song, 2017).

This is exemplified in work from Canterbury, New Zealand (Wilson \& Moore, 2017) that empirically evaluated on-site tourist decision making as a discursive performance (a socially embedded process), where frontline tourism staff members took leading roles. The objective of staff is to assure tourists' experiences that serve participants' multiple needs. The research revealed a "complex interplay of discursive skills, interpersonal strategies, and service attributes". The conversations with tourists assure "socially-embedded environments of trust”, leading to optimised decision-making, that is justifiable, and emotionally positive.

Hence, process research offers a valuable and complementary alternative to more conventional work.

There are good reasons to find that conventional models do not fully encompass the diverse processes involved in the production of tourist decisions (Smallman \& Moore, 2010).

Recreational tourism is characterised by heightened risks associated with uncertainties in experience outcomes, coupled to further uncertainties in what the tourist themselves seek in such experiences; is it exploration, play, or curiosity? This openness (vagueness even) contrasts markedly with strongly goal-directed intentional behaviours that are assumed in much decision-making theory.

Hence, the environmental context in which behaviours develop hugely influences the evolution of behaviours through the experience. The initially open expectations of tourists are further dynamic and shift nature throughout. Hence, expressed behaviour is strongly influenced by context. That noted, tourist decisions and behaviours are neither totally random nor completely arbitrary. Rather, the overall experience is generated by a complex interplay of the causal processes. As the behavioural pathevolves, these processes reflexively construct tourists' motives or objectives.

The spontaneity of much contextually-primed tourist behaviour and decision-making suggests that real-time decisions are characteristically "intuitive, spontaneous or impulsive, since they would not have been clearly articulated or prefabricated in consciousness” (Smallman \& Moore, 2010, p. 400).

However, it is not the case that judgments or decisions have not occurred. Work on human decision-making from an evolutionary perspective has established that "gut instincts" have their own logic (Brighton \& Gigerenzer, 2015; Gigerenzer, 2007; Gigerenzer \& Selten, 2002; Loock \& Hinnen, 2015; Mousavi 
\& Gigerenzer, 2014; Mousavi \& Kheirandish, 2015). Moreover, the behaviours generated by simple heuristics may appear "surprisingly rational, complex and coherent” (Smallman \& Moore, 2010, p. 400).

Tourism policy makers and industry actors presently tend to access rather constrained, often quantitatively-orientated consumer behaviour theories to develop forecasts of tourists' decision-making, and thence policy or business decisions. However, much of tourism decision-making simply does not follow statistically predictable models; this ignores the often-as-not quixotic nature of most tourism behaviours and tourists. Hence, we contend that conventional models of tourist decision-making may lead to ineffective tourism policy, marketing and management practices.

\section{A Naturalistic Decision-Making Model of Tourism Behaviour}

Previous work (Doscher et al., 2014; Moore, Smallman, Wilson, \& Simmons, 2012; Smallman \& Moore, 2010; Smallman et al., 2012) developed an agent-based simulation of tourists' behaviours in New Zealand. The simulation was based on an algorithm that mimicked naturalistic behaviours of tourists. Whilst many of the empirical findings of this work and subsequent studies have been published (Doscher et al., 2014; Smallman et al., 2012; Wilson \& Moore, 2017), the construction of a naturalistic decision-making model of tourism has not been fully articulated.

\section{Naturalistic Decision-Making}

Naturalistic decision-making deconstructs decision-making through detailed analyses of discourse, narrative and social action by decision-makers with a strong focus on context (Gore, Banks, Millward, \& Kyriakidou, 2006). It has been used extensively in the study of real-world decision makers, particularly in high-risk work environments (Elliott, 2005; Gore et al., 2006; Gore, Flin, Stanton, \& Wong, 2015; Klein, 1998; Lipshitz, Klein, \& Carroll, 2006; Lipshitz, Klein, Orasanu, \& Salas, 2001; McDaniel, 1993; Shattuck \& Miller, 2006; Zsambok \& Klein, 1997). It attempts to describe what people do under pressure of time, ambiguous or absent information, poorly-defined goals, and an evolving context (Klein, 1997). Further, it describes how people can use their experience (in the form of heuristics) to arrive at good decisions without the need to compare potential positive and negative outcomes of a course of action. Also, it is, if rather obviously, "naturalistic", in that it is drawn from the real world. Additionally, naturalistic decision-making offers guidance for training people to make better decisions or to help others to make better decisions. Finally, its tacit acceptance of the role of the discursive mind (Edwards \& Potter, 1992; Harré \& Gillett, 1994; Moore, 2002) in decision-making represents a marked departure from earlier decision-making paradigms (Smallman \& Moore, 2010, pp. 401-402). Woodside, MacDonald, and Burford (2004) and Decrop (2006) implicitly follow this approach in their naturalistic accounts of tourism decision-making.

In this paradigm decision-making is not about rational choice. We all develop heuristics through which we make decisions. These heuristics are the product of lived or simulated experiences, including learning and training (indeed the etymology of the word is the Greek $\varepsilon v \rho ı \kappa \alpha$ ("I have found")). We use heuristics to make decisions based on interpreting patterns that we perceive in cues (signals) that we perceive in the context in which we work and live (see Figure 1). Cues are experienced through the human senses (taste, sight, touch, smell, and sound).

Klein (1997) synthesises a rather more precise definition of the process (see Figure 2). One of the co-creators of the naturalistic decision-making paradigm, he refers to his version of naturalistic decision-making as recognition-primed decision-making (RPD). 


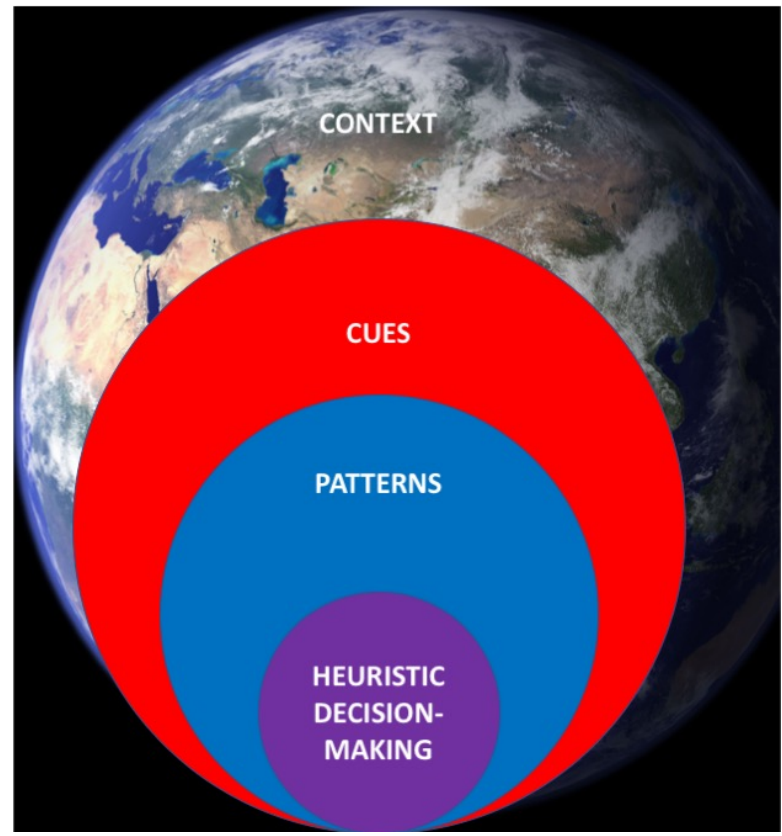

Figure 1. Naturalistic decision-making.

Level 1

Simple Match

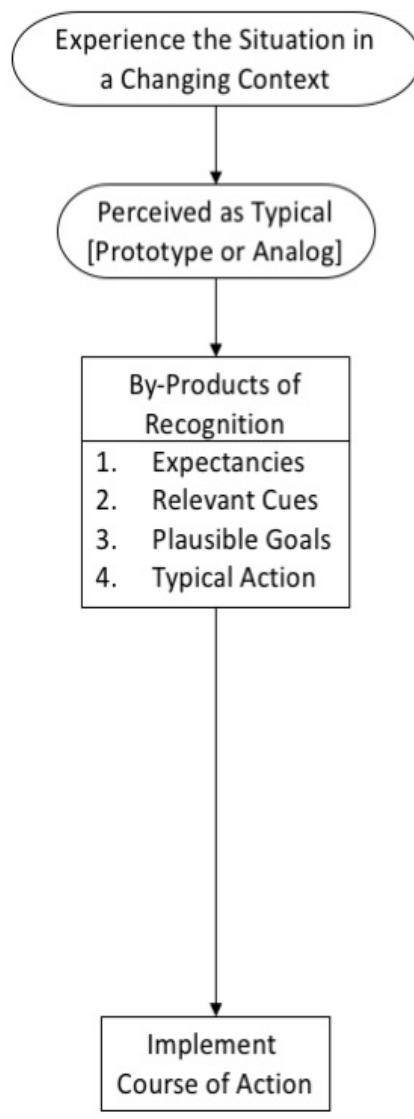

Level 2

Diagnose the Situation

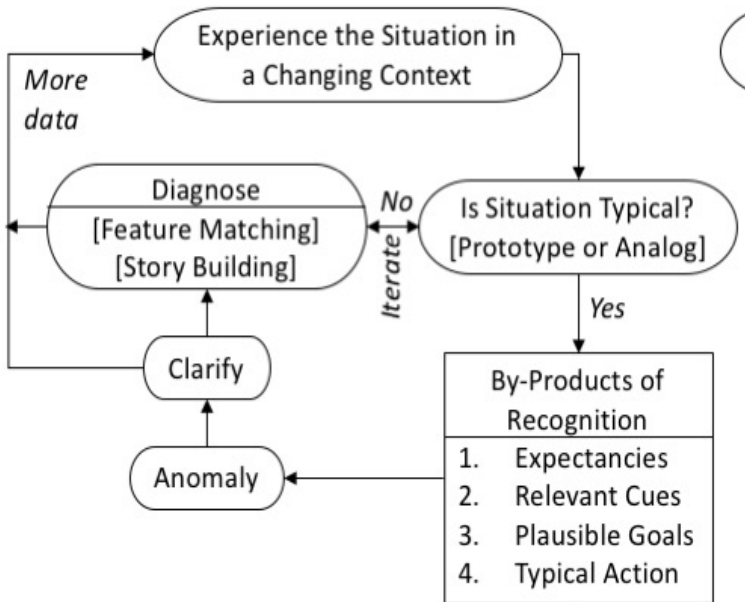

Level 2

Evaluate the Course of Action a Changing Context

Perceived as Typical

[Prototype or Analog]

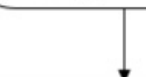

By-Products of Recognition

1. Expectancies

2. Relevant Cues

3. Plausible Goals

4. Action 1...n

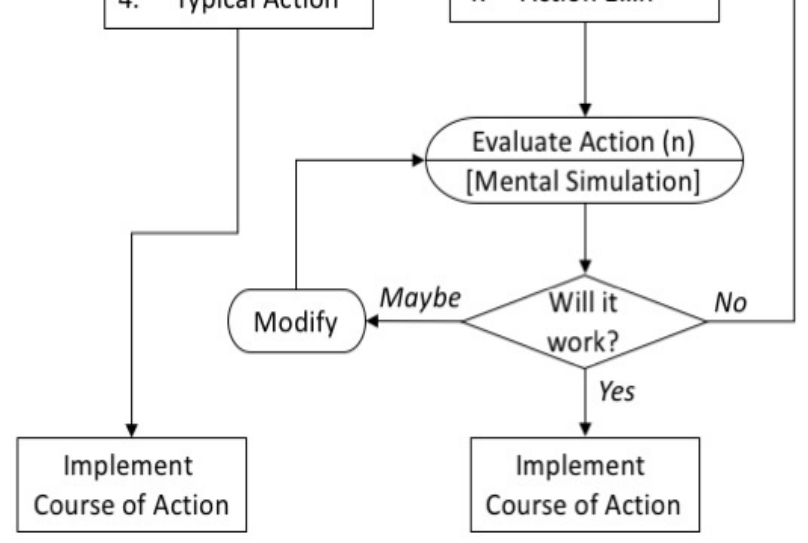

Figure 2. Recognition-primed decision model (after Klein (1997, p. 286)). 
In Level 1-the Simple Match - the decision-maker identifies a situation in which the goals are clear, the critical cues are being monitored, expectations about the future form, and an appropriate action is recognised. The decision-maker reacts accordingly.

In Level 2-Diagnose the Situation —uncertainty about the situation (based on relevant cues) promotes diagnostic activity. The aim is to either compare alternative explanations of the situation or to identify the source of anomalies. Decision-makers may use different heuristics in their diagnosis: matching features that they have previous experience of; or building a plausible story to make sense of cues (Maitlis, 2005).

Level 3-Evaluate the Course of Action-is a more complex case, requiring the decision-maker to mentally simulate likely outcomes of a course of action. The aim is to identify negative outcomes that exceed the decision-maker's expectancies and to either modify an action or evaluate a new one.

\section{Naturalistic Decision-Making and Tourism: The Need to Nudge?}

Before contemplating how to deploy naturalistic decision-making in tourism, we need to introduce one further enabling piece of science from psychology and behavioural economics.

Thaler and Sunstein (2008) propose the idea of "nudges" as a mechanism to enable libertarian paternalism. They contend that usually people should be free to do what they want and to opt out of things that they do not like. At the same time, it is legitimate for "choice architects" to attempt to influence people's behaviours so that they may improve their lives (based on public policy, market research or similar).

Choice architecture then is focused on presenting choices in a manner that will influence decisions. The principle is to "nudge" people without taking away their freedom of choice. For example, Thaler and Sunstein (2008) proposed to increase organ donation rates in the United States of America. They contended that a mandated choice program be put in place, where, for someone to renew their driving license, they must indicate whether they would like to be an organ donor or not. Thaler and Sunstein (2008) further suggested the creation of websites suggesting that the wider community supports organ donation to nudge people to become organ donors themselves.

In the language of naturalistic decision-making (or recognition-primed decision-making) nudging is concerned with managing expectancies, cues, plausible goals, and potential actions.

How might these ideas apply in tourism?

There is known to be a problem of marine debris pollution linked to visitation in Australia's southern Great Barrier Reef (Wilson \& Verlis, 2017). Tourists are the greatest source of debris (e.g., cigarette butts) from publicly accessible islands. They also influence debris loads on nearby uninhabited islands. On Heron Island, sites close to amenities had greater levels of tourist-sourced debris. The researchers responsible for this study (Wilson \& Verlis, 2017) identify several solutions (e.g., increased education of visitors to the region to the problem of marine debris or the introduction of portable beach ashtrays), but they also call for "education" that "targets user beliefs and attitudes which can then lead to a significant pro-environmental behaviour, and potential changes to personal norms" (p. 245).

Nudge theory coupled to the naturalistic decision-making paradigm would likely find more success in investment in physical cues above education. The logic is that if people are presented with blatant opportunities to dispose of debris properly (portable ashtrays or garbage bins) they are likely to use them. On the other side of the argument who wants to be lectured on "pro-environmental behaviour"? Moreover, changes to personal norms (habits) are not easily achieved (Lally \& Gardner, 2013), and certainly not in a short stay at a tourist location. 
This requires a policy choice architecture to be put in place - to fund the ashtrays and bins. Yet, there is more to nudging for improved decision making here than that. The frontline staff can model behaviours and set cues themselves.

Training frontline staff in naturalistic decision-making will enable them to better work with tourists to achieve both policy objectives and tourists' desires. Training tourism policy makers and regulators should result in better policy and policy outcomes.

Nudging with an understanding of naturalistic decision-making should further allow policy makers and regulators to attend to the effects of the forces that we noted at the beginning of this paper.

\section{References}

Arlt, W. G. (2015). China's outbound tourism in 2015: Another year of resilient growth and new trends. Forbes Asia Blog. Retrieved from https://www.forbes.com/sites/profdrwolfganggarlt/2015/12/30/2015-year-of-resilient-growth-and-further-segmentation-of-ch inas-outbound-tourism/\#1ee85216bc11 [1 Feburary 2018]

Beall, G. (2017). Eight key differences between Gen Z and Millennials. Huffington Post, The Blog. Retrieved from https://www.huffingtonpost.com/george-beall/8-key-differences-between_b_12814200.html [1 February 2018]

Becken, S., \& Simmons, D. (2008). Using the concept of yield to assess the sustainability of different tourist types. Ecological Economics, 67(3), 420-429.

Brighton, H., \& Gigerenzer, G. (2015). The bias bias. Journal of Business Research, 68, 1772-1784.

CNT Editors. (2017). Fourteen emerging destinations around the world. Conde Nast Traveller. Retrieved from https://www.cntraveler.com/gallery/emerging-destinations-around-the-world [1 February 2018]

Colomo-Palacios, R., García-Peñalvo, F. J., Stantchev, V., \& Misra, S. (2017). Towards a social and context-aware mobile recommendation system for tourism. Pervasive and Mobile Computing, 38(2), 505-515.

Decrop, A. (2006). Vacation decision making.Wallingford: CABI.

Dobbs, R., Manyika, J., \& Woetzel, J. (2015). No ordinary disruption. The four global forces breaking all the trends. New York: Public Affairs.

Doscher, C., Moore, K., Smallman, C., Wilson, J., \& Simmons, D. (2014). An agent-based model of tourist movements in New Zealand. In A. Smajgl and O. Barreteau (Eds.), Empirical agent-based modelling—challenges and solutions (pp. 39-51). New York: Springer.

Dwyer, L., Edwards, D., Mistilis, N., Romand, C., \& Scott, N. (2009). Destination and enterprise management for a tourism future. Tourism Management, 30(1), 63-74.

Edwards, D., \& Potter, J. (1992). Discursive psychology. London: Sage Publications Ltd.

Elliott, T. (2005). Expert decision-making in naturalistic environments: A summary of research (DSTO-GD-0429). Edinburgh, SA: Australian Government, Department of Defence, Defence Science and Technology Org.

Espiner, S., \& Becken, S. (2013). Tourist towns on the edge: Conceptualising vulnerability and resilience in a protected area tourism system. Journal of Sustainable Tourism, 22(4), 1-20.

Fuggle, L. (2017). Gen Z will soon transform the travel industry. Huffington Post, The Blog. Retrieved from https://www.huffingtonpost.com/lucy-fuggle/gen-z-are-going-to-transf_b_9870028.html [1 February 2018]

Fuller, E. (2017). How India has become a booming supplier of outbound tourists. Forbes, Business/\#Wanderlust. Retrieved from https://www.forbes.com/sites/edfuller/2017/03/14/ignore-india-at-your-peril/\#3defe5ae4225 [1 February 2018]

Gigerenzer, G. (2007). Gut feelings. The intelligence of the unconscious. London: Penguin Allen Lane.

Gigerenzer, G., \& Selten, R. (Eds.). (2002). Bounded rationality: The adaptive toolbox. Cambridge, MA: MIT Press.

Gigerenzer, G., Todd, P. M., \& the ABC Research Group. (1999). Simple heuristics that make us smart. New York: Oxford University Press.

Glover, T. D., \& Stewart, W. P. (2013). Advancing healthy communities policy through tourism, leisure, and events research. Journal of Policy Research in Tourism, Leisure and Events, 5(2), 109-122.

Gore, J., Banks, A., Millward, L., \& Kyriakidou, O. (2006). Naturalistic decision-making and organisations: Reviewing pragmatic science. Organization Studies, 27(7), 925-942.

Gore, J., Flin, R., Stanton, N., \& Wong, B. L. W. (2015). Editorial. Applications for naturalistic decision-making. Journal of Occupational and Organizational Psychology, 88(2), 223-230. 
Gratton, L., \& Scott, A. (2016). The 100-year life: Living and working in an age of longevity. London: Bloomsbury.

Gulbahar, M. O., \& Yildirim, F. (2015). Marketing efforts related to social media channels and mobile application usage in tourism: case study in Istanbu. Procedia-Social and Behavioral Sciences, 195, 453-462.

Harré, R., \& Gillett, G. (1994). The discursive mind. Thousand Oaks, CA: Sage Publications, Inc.

Jun, S. H., \& Vogt, C. (2013). Travel information processing: Applying a dual-process model. Annals of Tourism Research, 40, 191-212.

Kahneman, D. (2011). Thinking fast and slow. New York: Macmillan.

Klein, G. A. (1997). The recognition-primed decision (RPD) model: Looking back, looking forward. In C. E. Zsambok and G. Klein (Eds.), Naturalistic decision making (pp. 285-292). Mahwah, NJ: Lawrence Erlbaum Associates, Publishers.

Klein, G. A. (1998). Sources of power: How people make decisions. Cambridge: MIT Press.

Lally, P., \& Gardner, B. (2013). Promoting habit formation. Health Psychology Review, 7(1), S137-S158.

Leiper, N. (2004). Tourism management (3rd ed.). Malaysia: Pearson Education, Australia.

Li, C., McCabe, S., \& Song, H. (2017). Tourist choice processing: Evaluating decision rules and methods of their measurement. Journal of Travel Research, 56(6), 699-711.

Lin, D., \& Simmons, D. (2017). Structured inter-network collaboration: Public participation in tourism planning in Southern China. Tourism Management, 63, 315-328.

Lipshitz, R., Klein, G., \& Carroll, J. S. (2006). Introduction to the special issue. Naturalistic decision making and organisational decision-making: Exploring the intersections. Organization Studies, 27(7), 917-924.

Lipshitz, R., Klein, G., Orasanu, J., \& Salas, E. (2001). Taking stock of naturalistic decision making. Journal of Behavioural Decision Making, 14, 331-352.

Loock, M., \& Hinnen, G. (2015). Heuristics in organizations: A review and a research agenda. Journal of Business Research, 68, 2027-2036.

Maitlis, S. (2005). The social process of organizational sensemaking. Academy of Management Journal, 48(1), 21-49.

McCabe, S., Li, C. S., \& Chen, Z. (2016). Time for a radical reappraisal of tourist decision making? Toward a new conceptual model. Journal of Travel Research, 55(1), 3-15.

McDaniel, W. C. (1993). Naturalistic group decision-making: Overview and summary. In J. N. J. Castellan (Ed.), Individual and group decision-making: Current issues (pp. 200-216). Hillside, NJ: Lawrence Erlbaum Associates.

Moore, K. (2002). The discursive tourist. In G. M. S. Dann (Ed.), The tourist as a metaphor of the social world (pp. 41-59). Wallingford, Oxon: CABI Publishing.

Moore, K., Smallman, C., Wilson, J., \& Simmons, D. (2012). Dynamic in-destnation decision-making: An adjustment model. Tourism Management, 33(3), 635-645.

Mousavi, S., \& Gigerenzer, G. (2014). Risk, uncertainty, and heuristics. Journal of Business Research, 67, 1671-1678.

Mousavi, S., \& Kheirandish, R. (2015). Behind and beyond a shared definition of ecological rationality: A functional view of heuristics. Journal of Business Research, 67, 1780-1785.

Nikitin, O., \& Vorontsova, G. (2015). Aging population and tourism: Socially determined model of consumer behavior in the "senior tourism" segment. Procedia-Social and Behavioral Sciences, 214, 845-851.

Saha, S., \& Yap, G. (2014). The moderation effects of political instability and terrorism on tourism development. Journal of Travel Research, 54(4), 509-521.

Shattuck, L. G., \& Miller, N. L. (2006). Extending naturalistic decision making to complex organisations: A dynamic model situated cognition. Organization Studies, 27(7), 989-1010.

Shone, M. C., Simmons, D. G., \& Dalziel, P. (2016). Evolving roles for local government in tourism development: A political economy perspective. Journal of Sustainable Tourism, 24(12), 1674-1690.

Smallman, C., \& Moore, K. (2010). Process studies of tourists' decision-making: The riches beyond variance studies. Annals of Tourism Research, 37(2), 397-422.

Smallman, C., Moore, K., Wilson, J., \& Simmons, D. (2012). Case studies of international tourists' in-destination decision-making processes in New Zealand. In K. F. Hyde, C. Ryan, and A. G. Woodside (Eds.), Field guide to case study research in tourism, hospitality and leisure (pp. 297-318). Bingley, West Yorkshire: Emerald Group Publishing.

Thaler, R. H., \& Sunstein, C. R. (2008). Nudge: Improving decisions about health, wealth, and happiness. New Haven, CT: Yale University Press.

Tsiotsou, R., \& Ratten, V. (2010). Future research directions in tourism marketing. Marketing Intelligence \& Planning, 28(4), 533-544. 
Urh, B. (2015). Helathy lifestyle and tourism. Quaestus, (6), 132-143.

Veiga, C., Santos, M. C., Águas, P., \& Santos, J. A. C. (2017). Are millennials transforming global tourism? Challenges for destinations and companies. Worldwide Hospitality and Tourism Themes (in press).

Wilson, J., \& Moore, K. (2017). Performance on the frontline of tourist decision making. Journal of Travel Research, 57(3), 370-383.

Wilson, S. P., \& Verlis, K. M. (2017). The ugly face of tourism: Marine debris pollution linked to visitation in the southern Great Barrier Reef, Australia. Marine Pollution Bulletin, 117(1-2), 239-246.

Woodside, A. G., MacDonald, R., \& Burford, M. (2004). Grounded theory of leisure travel. Journal of Travel and Tourism Marketing, 14(1), 7-39.

Zeng, G., \& Go, F. (2013). Evolution of middle-class Chinese outbound travel preferences: An international perspective. Tourism Economics, 19(2), 231-243.

Zsambok, C. E., \& Klein, G. A. (Eds.). (1997). Naturalistic decision making. Mahwah, NJ: Erlbaum. 